\title{
Rhinology Future Debates, an EUFOREA Report*
}

Wytske J. Fokkens', Claus Bachert², Manuel Bernal-Sprekelsen³, Jean Bousquet ${ }^{4}$, Michel Djandji ${ }^{5}$, Alejandro Dorenbaum ${ }^{6}$, Dorna Hakimi-Mehr', Stuart Hendry ${ }^{8}$, Claire Hopkins ${ }^{9}$, Andreas Leunig ${ }^{10}$, Leda Mannent ${ }^{11}$, Dirk Mucha ${ }^{12}$, Metin Onerci ${ }^{13}$, Benoit Pugin ${ }^{14}$, Sanna Toppila-Salmi ${ }^{15}$, Paul Rowe ${ }^{16}$, Sven F. Seys ${ }^{14}$, Susan Stimson ${ }^{17}$, Agnieszka Strzembosz ${ }^{18}$, Peter W. Hellings ${ }^{1,19}$
Rhinology 55: 298-304, 2017

https://doi.org/10.4193/Rhino17.221

* Received for publication:

October 10, 2017

Accepted: October 15, 2017

This meeting was held on

8 December 2016, Brussels, Belgium

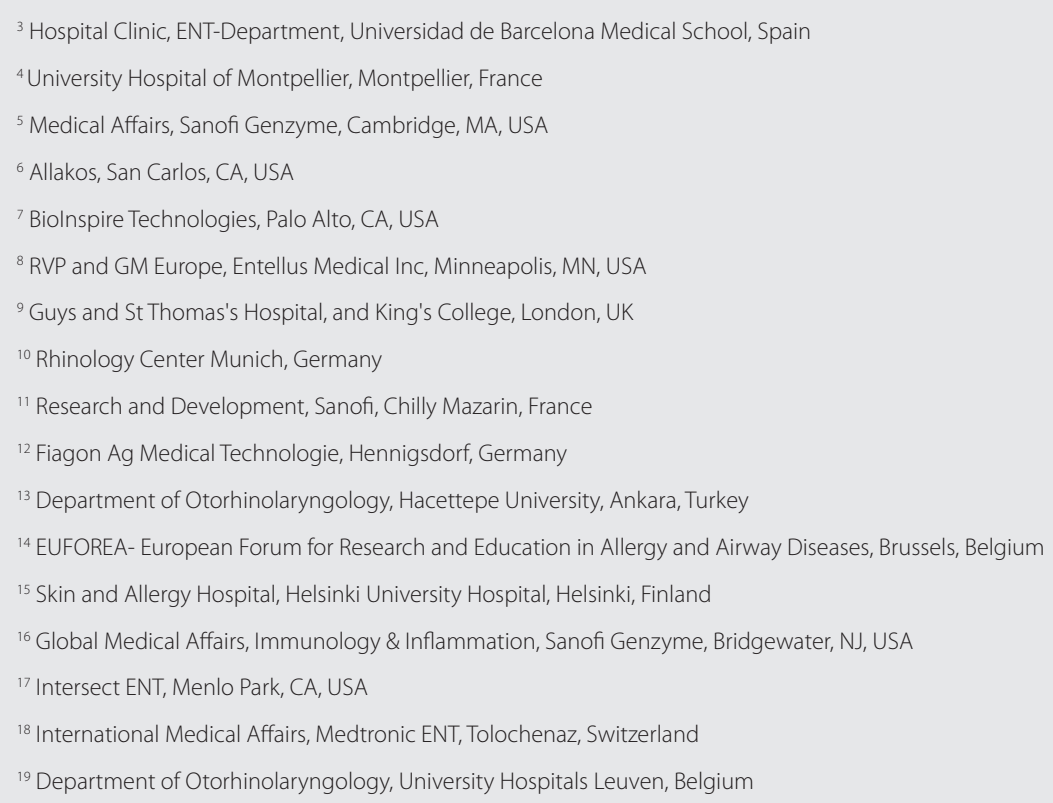

\section{Abstract}

The first Rhinology Future Debates was held in Brussels in December 2016, organized by EUFOREA (European Forum for Research and Education in Allergy and Airways diseases). The purpose of these debates is to bring novel developments in the field of Rhinology to the attention of the medical, paramedical and patient community, in a highly credible and balanced context.

For the first time in Rhinology, a peer to peer scientific exchange with key experts in the field of rhinology and key medical colleagues from leading industries let to a brainstorming and discussion event on a number of hot issues in Rhinology. Novel developments are presented by key experts from industry and/or key thought leaders in Rhinology, and then followed by a lively debate on the potential positioning of new developments in care pathways, the strengths and weaknesses of the novel development(s), and comparisons with existing and/or competing products, devices, and/or molecules.

As all debates are recorded and distributed on-line with limited editing (www.rhinology-future.com), EUFOREA aims at maximizing the education of the target groups on novel developments, allowing a critical appraisal of the future and a more rapid implementation of promising novel tools, techniques and/or molecules in clinical practise in Europe.

The next Rhinology Future debate will be held in Brussels in December 2017. 


\section{Introduction}

For the first time in Rhinology, EUFOREA brought together key experts in the field of rhinology and key medical persons from the leading industries for a brainstorming and discussion forum in Brussels. The topics that had been chosen for the debates reflect some of the current future trends in every day practise: biological treatment for CRSwNP, drug-eluting devices for CRS, navigation systems for sinus surgery, and balloon sinus dilatation.

During 4 sessions of 1 hour, specific novel topics in Rhinology, that were fully recorded and distributed on-line via the Rhinology future debates (www.rhinology-future.com, Figure 1) and EUFOREA (www.euforea.eu) websites.

The purpose of this report is to summarize the major discussion points raised by the key opinion leaders that took part in the debates, and pave the way for a better and close collaboration between the medical community, the industry and even patient in the future.

The next Rhinology Future debate will be held in Brussels on Dec. 8, 2017.

\section{New developments in biologicals for CRSwNP}

In the first session, Professor Claire Hopkins highlighted the present unmet needs in the treatment of patients with CRSwNP (1-4). She pointed out that the treatment heavily relies on corticosteroids, which when given systemically are effective but only for a limited time period ${ }^{(5-7)}$. Repeated use of systemic corticosteroids is restricted by potential serious side effects like osteoporosis and the development of diabetes and hypertension. Surgery is effective and the benefit remains relatively stable over time, however the revision rate is between $10 \%$ and $20 \%$ in 5 years ${ }^{(8-10)}$ and up to $40 \%$ remain uncontrolled at 3 years after FESS (11). The treatments we have available at the moment, such as corticosteroids and antibiotics ${ }^{(12,13)}$ are relatively cheap and new treatment options need to be clinically effective as well as cost-effective. Monoclonal antibodies could be a potential new treatment when we can find the patients with the phenotype and endotype that will most benefit from these treatments. The ability to predict which patients will respond favourably to a certain monoclonal antibody will be a key issue in achieving costs-effectiveness.

Two monoclonal antibodies were discussed in more detail: anti-IL4R $\alpha$ blocker Dupilumab (Sanofi) that blocks the IL4/IL13 receptor/ligand system ${ }^{(14)}$ and AK001 (Allakos) that selectively blocks the Siglec-8, an inhibitory receptor that is present on mast cells and eosinophils ${ }^{(15)}$.

The discussion started off with the key question of positioning monoclonal antibodies in the treatment of CRSwNP in the future especially in comparison to surgery ${ }^{(16)}$. The prevalence of CRSwNP is about 4-5\% in the adult population ${ }^{(17)}$. We do

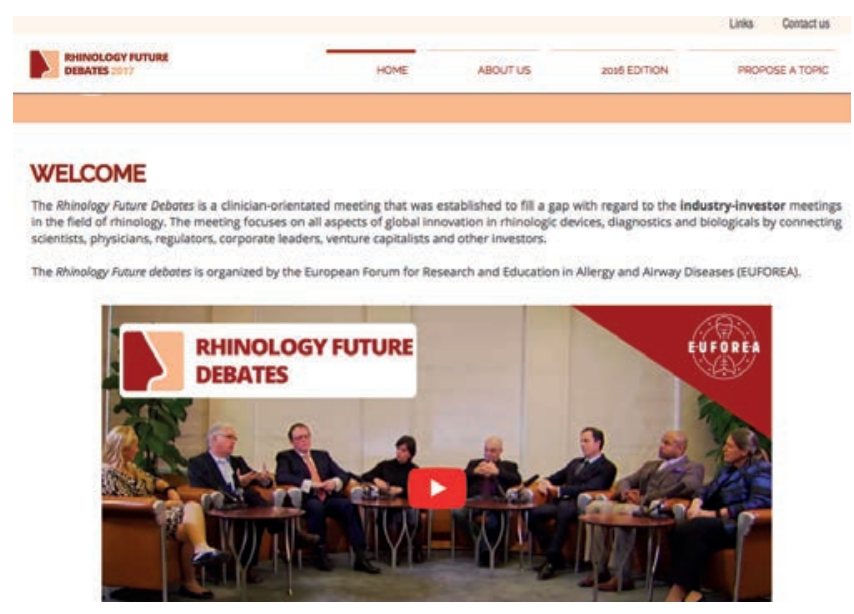

Figure 1. Website of the rhinology future debates (www.rhinologyfuture.com), where videos from the different panel discussion can be watched.

not know the exact prevalence of patients with severe disease needing repetitive surgery but Prof. Bachert estimated this to be around $1 \%$ of the population.

While surgery can be very effective, there is a group of patients that needs multiple revision procedures. Such patients, who already have had repetitive surgery, are very interested to find alternatives. We would like to be able to discriminate the patients that will not react favourably to surgery but will respond to a certain monoclonal antibody to improve cost-effectiveness. However, it was pointed out that improving the Quality of Life $(\mathrm{QOL})$ of our patients, that are now often untreatable, is also very important.

In chronic inflammatory respiratory disease, like CRSwNP and asthma, both the impact on QOL of the patients and the costs of the treatment will lead to data looking at costs per Quality adjusted Life Year (QALY).

We still have an issue that the impact of the disease CRSwNP on QOL but also economically is not perceived as significant as, for example, in cardiovascular disease or diabetes. For that reason, it was emphasized that in clinical trials it is important to have standardised endpoints with emphasis on QOL, like SNOT-22 and level of control of disease additional to polyp size ${ }^{(2)}$. It is especially important to have measurements that can be used to compare to other diseases, like general QOL questionnaires and impact on work productivity ${ }^{(18-21)}$. In registration trials, however, we are dependent on what the health authorities ask us, which is preferentially polyp size and symptoms.

It was emphasized that evaluation of direct and indirect costs in large cohorts of patients in daily clinical care are needed to have a better understanding of the economic impact of the disease $(18,22)$. Especially, because most patients with CRSwNP are in the age group of the working population. Moreover, biologicals also impact the symptoms of lower airway disease in patients with 


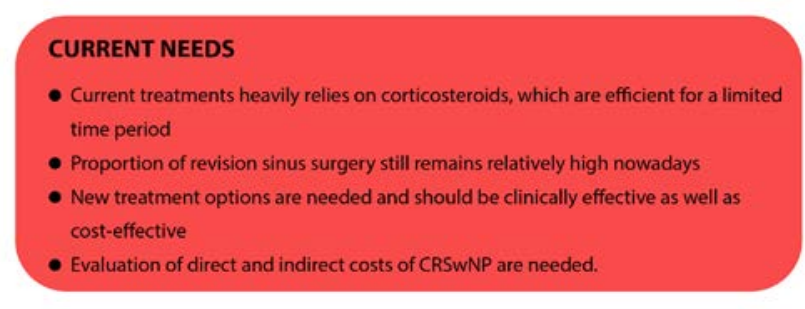

INDUSTRIAL SOLUTIONS

\begin{tabular}{cccc}
\hline Industry & Product & Type & Target \\
\hline Sanofi & Dupilumab & Monoclonal antibody & anti-IL4Ra \\
\hline Allakos & AK001 & Monoclonal antibody & Siglec-8 \\
\hline
\end{tabular}

\section{DISCUSSION POINTS}

- Development of biomarkers to predict which patients will react favourably to monoclonal antibodies (mAb)

- More studies are needed to determine long term efficacy and cost-effectiveness of mAb

- Determine the position of mAb within the current treatment algorithm of CRS

Figure 2. Summary of the panel discussion on "New developments in biologicals for CRSwNP".

co-morbidity and may have additional value in these patients.

A collaboration of the health professionals, the industry and the government could be ideal to follow a large cohort of patients to understand the impact of the disease not only on work productivity but also the impact that the (treatment of) the disease can have in the longer run. It could also lead to the development of instruments that are internationally accepted by all parties to optimally measure impact of the disease.

The panel was asked whether at the moment we have sufficient evidence for safety and efficacy for monoclonal antibodies. At this moment, we do not have registration/licencing for monoclonal antibodies for CRSwNP. However, there seems to be reasonable amount of data to show that monoclonal antibodies are safe, especially in the asthma literature in the literature concerning asthma, chronic urticaria and atopic dermatitis ${ }^{(23,24)}$. We need more studies in larger groups of patients to demonstrate that monoclonal antibodies are safe over longer periods of time ${ }^{(25)}$.

Although we are able to endotype patients at the moment, we still need to combine that knowledge with the development of biomarkers to predict which patients will react favourably to monoclonal antibodies ${ }^{(26)}$. Ideally, we should be able to discriminate these patients early in the disease and treat them early to prevent multiple surgeries in the years to follow and potentially also to prevent the development of lower airway disease ${ }^{(27,28)}$. Although, contrary to surgery, we currently do not have enough data at the moment to show that monoclonal antibodies can prevent the development of asthma from a pathophysiological point of view, this seems very feasible. In this way, we will be able to deliver precision medicine to our patients tailoring the most (cost) effective treatment to our patients preferably early in the disease process ${ }^{(21,29)}$. Most of the surgeons in the panel believed that in the future the amount of surgery will be significantly reduced and hopefully seldom be necessary, although they were not sure whether in some patients a singular surgery can be sufficient to prevent further development of the disease. However, this is very much dependent on the type of surgery; surgery approaches need to be tailored to the endotype/severity of inflammation in the future.

The panel concluded that there is a huge potential for monoclonal antibodies in the treatment of patients with CRSwNP but that there is a need to collaborate together to show the burden of disease and the burden of treatments that we offer to our patients so to establish real personalised medicine to our patients (Figure 2).

\section{Balloons in sinus surgery in Europe}

In the second session, we discussed the role of balloons in the treatment of CRS in Europe. Two examples of the potential role of balloons in the treatment of CRS were given.

Entellus medical technologies presented their vision to move surgical treatment of CRS from the operating theatre to the ambulatory setting by providing instruments like balloons and instruments for suction and irrigation ${ }^{(30,31)}$. Medtronic provided the evidence available for the use of balloon sinus dilation. It was shown that flexible balloons often miss the natural ostium ${ }^{(32)}$. For that reason, Medtronic developed a more rigid and image-guided balloon system.

Finally, an example was shown of the SinuSys Vent-os system, a slow low-pressure balloon which further emphasizes the possibilities of ambulatory treatment.

Balloons can be combined with image-guidance to improve accuracy. However, there is still a debate going on about the precise indications and limitations of the technique.

The panel agreed that the balloon is an instrument that still needs to find its exact place in the treatment of CRS.

The panel felt that potentially good candidates for balloon procedures could be patients with sinus obstruction and not primarily mucosal disease, special cases of acute rhinosinusitis, re-closure after surgery, approach in the office, relatively short procedures (less than one hour) in the office, giving the options of applying medication in sinus via balloon. The panel members were all confident that the patients suitable for balloon are not the same population as the patients suitable for FESS. Also, panellists expressed their worries about the potential stretching of indication for an intervention. At the moment, the panellists do not see indications for balloons in patients with severe CRS with mucosal disease like patients with CRSwNP. 


\section{INDUSTRIAL SOLUTIONS}

\begin{tabular}{llc}
\hline Industry & Product & Type \\
\hline $\begin{array}{l}\text { Entellus } \\
\text { Medical }\end{array}$ & XprESs $^{\mathrm{M}}$ & Multi-Sinus Dilation Systems \\
\hline Medtronic & NuVent $^{\mathrm{TM}}$ & EM Sinus Dilation System \\
\hline SynuSys & Vent-Os $^{*}$ & Sinus Dilation System \\
\hline
\end{tabular}

\section{DISCUSSION POINTS}

- In Europe, the non-reimbursement of the balloons are considered problematic

- A better selection of patients suitable for balloon is extremly important

- Large randomized trials are needed to obtain a better understanding of the

possibilities and limitation of balloons

Figure 3. Summary of the panel discussion on "Balloons in sinus surgery in Europe".

A problem in Europe is the reimbursement of the balloon. Although in general the panellists feel it is potentially not an issue to add costs to the procedure, just like we use shaver blades, at the moment most balloons are very expensive compared to the total reimbursement. Although, it was noted during the discussion that NICE, the National Institute for Clinical Excellence, was considering the utilization of the Entellus balloon technology in the UK's NHS.

The panellists are not convinced that the potential advances of low-pressure balloon technology, achieves sufficient trade-off with the relatively longer time the procedure takes.

The trials available at the moment suffer from lack of control groups, lack of randomisation, short-term follow-up and type II-error (not different is not the same as equal). The panellists would like to see randomised trials with balloons in large patients groups, preferably sham-controlled but otherwise in comparison with a FESS and a medical treatment arm and with long-term follow-up. The trials should be in a variety of welldefined patient groups to be sure that the results are widely applicable.

Relatively flexible balloons seem to be inherently safe procedures; however, the more rigid balloons, and introducers, seem to have higher risks. The potential risks of penetration of the skull base and orbit are not unthinkable, cases have been reported ${ }^{(33,34)}$. Of course, complications are always made by the surgeon and not by the instrument.

We conclude that data to guide us in patient selection are extremely important. We need good large randomized trials to give us a better understanding of the possibilities and the limitations of balloons. Cost-effectiveness should be part of those studies (Figure 3).

\section{Local treatment in CRS: Higher dose, longer availa- bility}

In the third session, we addressed the need for higher dose of local treatment in the sinuses. Two examples of high dose corticosteroid implants were presented. First the PROPEL ${ }^{\oplus}$ device from Intersect ENT was presented ${ }^{(35,36)}$. Bioinspire presented sinuband, a new bioabsorbable film that slowly delivers corticosteroids postoperatively ${ }^{(37)}$.

It is indicated by the panel that these are promising new developments to reduce systemic corticosteroids use while potentially getting a higher dose in the sinuses. We also see great opportunities in treating frontal sinus disease difficult to reach with local treatment and as an alternative to local treatment especially in cases where compliance is an issue. PROPEL implants are both FDA and CE mark approved for use in both ethmoid and frontal sinuses and the evidence supporting the technology was presented. It was mentioned that the Sinuband could have potential to cover bare bone especially in (more aggressive) frontal sinus surgery to provide a layer for the epithelium to grow over. However, it was commented that synechia formation in general does not seem to be a big issue in most of our patients ${ }^{(38)}$. Moreover, as was shown in the past ${ }^{(39)}$ it takes months for lateralisation of the middle turbinate after surgery and there are easy ways to prevent this lateralisation ${ }^{(40)}$.

The panel discussed the differences between device and drug and the different regulations in Europe. We discuss that we are in need of data comparing these new local ways of treatment with the conventional ways of local treatment, like nasal douches with steroids or nasal sprays for longer periods of time and in different pheno- and endotypes.

The panellists express their interest in products that can be used directly after surgery and deliver a high dose of steroids especially in the postoperative period, preferably for a longer period of 1-3 months but also in products that can easily be administered in the outpatient office setting ideally by placing a device/drug in between the polyps to deliver high doses of drug locally. The studies until now do show that it is not a problem to rinse extensively after placing the devices. The drugs are so lipophilic that it is not very likely that they are washed out. Also, the devices stay nicely in place when patients used rinsing ${ }^{(35-37)}$.

Some panellists indicated that they felt corticosteroids could reduce epithelial regrowth and that it is important to keep the bone covered with mucosa as much as possible. They indicated that these devices would be able to leave more of the mucosa and rely on the anti-inflammatory effects of the drug. Other panellists voiced they do not worry at all about epithelial regrowth and point to studies actually improving the quality and growth of the mucosa after local corticosteroid usage ${ }^{(41-43)}$. Animal experimental studies, performed with Sinuband on mucosa or on stripped bone, showed that the device does not have a negative effect on wound healing (unpublished data). It is debated how much steroids are actually reaching the 


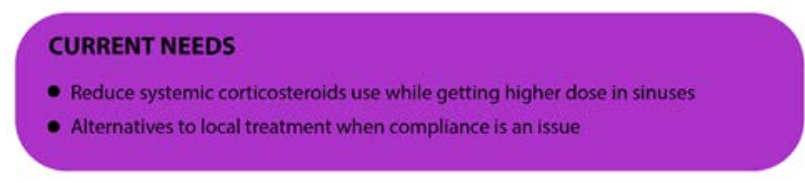

INDUSTRIAL SOLUTIONS

\begin{tabular}{ccc}
\hline Industry & Products & Type \\
\hline Intersect ENT & PROPEL' \& RESOLVE & Steroid releasing implants \\
\hline $\begin{array}{c}\text { Biolnspire } \\
\text { Technologies }\end{array}$ & SinuBand $^{\text {TM }}$ & Steroid relasing adhesive film \\
\hline
\end{tabular}

\section{DISCUSSION POINTS}

- Promising technologies to deliver high dose steroids in the postoperative period

- Data comparing these new local ways of treatment with the conventional one are needed for longer periods of time and in different pheno- and endotypes.

Figure 4. Summary of the panel discussion on "Local treatment in CRS: Higher dose, longer availability".

mucosa. When the devices are placed in the sinuses, higher doses can be found in the sinuses and lower doses in the nasal cavity. Systemic exposure does not seem to be an issue for these devices ${ }^{(35-37)}$.

We conclude that these devices are promising and that we are very happy to design together with key opinion leaders from the companies and (university) hospitals the protocols to further study their role in contemporary treatment of the different phenotypes and endotypes of CRS (Figure 4).

\section{The place of navigation in daily practice}

Seventy-five percent of the practices in the US now have navigation in comparison to almost 4000 hospitals and clinics (25\%) in Europe.

Two Image-guided surgery (IGS) systems were presented. The system of Medtronic and the Fiagon system. Dr A. Strzembosz, presenting the electro-magnetic system of Medtronic, pointed out that for the best performance and the best patient results familiarity with the navigation system and proper and regular usage are mandatory. Being unfamiliar with the system can lead to more stress than real help in situations that navigation could be of assistance. Navigation can be of help in complex procedures but also potentially to do more complete surgery. The navigation systems can support the decisions of the surgeon but can never replace his/her anatomical knowledge.

Dr. D. Mucha, presenting the Fiagon system, explained that also for him having the system in the clinical routine is important. The instruments are navigated at the tip to improve accuracy and ease of use.

Contrary to some other societies, the European Rhinologic Society until now decided not to produce guidelines on when to use navigation. The society felt that the surgeon remains responsible at all times (it is the surgeon that is behind the wheel) and that pointing to situations where the navigation could be or should be used would not be helpful.

The panel felt navigation can play a role in education and it can improve the learning curve. However, nobody felt that complications can be prevented by using a navigation system and this has also been shown in the literature ${ }^{(44)}$. Moreover, some panellists felt that it can might be a disadvantage and even dangerous when (younger) surgeons are so used to navigation, especially in a training situation, that they do not primarily rely on their anatomical knowledge. Younger surgeons should also be trained in using IGS in a proper way.

It was pointed out that FESS is the most litigated procedure in rhinology, but unfortunately navigation per se does not reduce the complication rate ${ }^{(44,45)}$.

The panellists felt it prudent that if navigation is used, to use it often to encourage familiarity with the technology and its limitations. However, it was not felt that the advantage of using IGS at the moment warrants its use in every case. If IGS is to be used it should be employed from the outset, to receive reconfirmation from the beginning of the surgery, in order to be comfortable with its use at a moment that it is most needed. The panel felt the IGS is helpful but not meant to help with millimetric decisions. It was pointed out numerous times that it is always the surgeon and his/her anatomical knowledge that is most important.

The question whether more complete surgery could be done with navigation was undecided. Surgeons having a more conservative philosophy perform less extensive surgery and believe that incomplete surgery does not mean less effective surgery. There are no data at the moment linking the extent of the surgery to patient outcomes.

Some panellists felt that navigation gives a more 3D feeling helping to improve their orientation.

When the panellists were asked what irritated them most when using IGS, they mostly mentioned technical issues; especially when it is unclear why the system does not work. Most panellists felt the systems were still too erratic.

Moreover, panellists expressed that they did not like the issues with data handling: patients coming from outside with the CT scan and then the navigation system needing another sinus CT to fulfil the criteria of the system. Most panellists thought the systems were expensive and although they understand the advantages of disposables, they were not happy with the costs of the disposables nor the limited use of re-usables.

Panellists expressed their frustration that systems very often seem to become less precise during the procedure, especially in more prolonged cases.

When asked what the panellists would really like to have in navigation the following items were mentioned: wireless systems, easy to use, easy registration, and also repetition of registration 


\section{DISCUSSION POINTS}

- Navigation can play an important role in education, to improve surgeons' learning curve

- Navigation provides different advantages, but it the surgeon and his/her

anatomical knowledge that should always prevail

- Navigation ideally should be cheaper, more realiable and user friendly.

Figure 5. Summary of the panel discussion on "The place of navigation in daily practice".

must be very easy.

Some panellists would like to have the possibility of seeing a $3 \mathrm{D}$ view in the navigation and it was suggested that it would be very helpful to have superposition the coronal view of the $C T$ superimposed on the endoscopic view.

Some panellists liked the ability of being able to make all instruments navigated, also disposable instruments at minimal costs, but others only used navigated pointers and/or suction.

Costs are a big issue, so companies should work on affordable systems and disposables.

The companies indicated that many of the irritations can and will be solved in the near future and that many of the dreams are worked on, like having wireless instruments. Some are a little bit more complicated like superimposing the coronal view on the endoscopic view.

The university KOLs again expressed that they think that guide- lines, position papers and recommendations for the use of navigation were not helpful and that for that reason the European bodies like EUFOREA or ERS are not planning to write these. It is concluded that navigation is certainly an advantage, we would not like to live without it, but ideally it should be cheaper, more reliable and user friendly. In the meantime, it was felt to be important to convince the health payers that the price is worth it and the use of navigation should be reimbursed (Figure 5).

\section{Conclusion}

For the first time in Rhinology, a peer to peer scientific exchange with key experts in the field of rhinology and key medical colleagues from leading industries let to a brainstorming and discussion event on a number of hot issues in Rhinology. All panellists felt the discussions were extremely valuable and a follow-up will be organized in December 2017.

\section{Authorship contribution}

WF, CB, JB and PH has designed the concept of the debates. WF has drafted the manuscript. WF, CB, MBS, MD, AD, DHM, $\mathrm{SH}, \mathrm{CH}$, $\mathrm{AL}, \mathrm{LM}, \mathrm{DM}, \mathrm{MO}, \mathrm{STS}, \mathrm{PR}, \mathrm{SS}, \mathrm{AS}, \mathrm{PWH}$ took part in the debates. All have critically reviewed the manuscript.

\section{Conflict of interest}

The Rhinology Future Debates were organized by EUFOREA without support of any of the pharmaceutical or medtech companies.

\section{References}

1. Hoehle LP, Phillips KM, Bergmark RW Caradonna DS, Gray ST, Sedaghat AR. Symptoms of chronic rhinosinusitis differentially impact general health-related quality of life. Rhinology. 2016;54(4):316-22.

2. Hopkins C, Philpott C, Crowe S, Regan S, Degun A, Papachristou I, et al. Identifying the most important outcomes for systematic reviews of interventions for rhinosinusitis in adults: working with Patients, Public and Practitioners. Rhinology. 2016;54(1):20-6.

3. Bousquet J, Bachert C, Canonica GW, Casale TB, Cruz AA, Lockey RJ, et al. Unmet needs in severe chronic upper airway disease (SCUAD). J Allergy Clin Immunol. 2009;124(3):428-33.

4. Hellings PW, Fokkens WJ, Akdis C, Bachert C Cingi C, Dietz de Loos D, et al. Uncontrolled allergic rhinitis and chronic rhinosinusitis: where do we stand today? Allergy. 2013:68(1):1-7.

5. Chong LY, Head K, Hopkins C, Philpott C, Schilder AG, Burton MJ. Intranasa steroids versus placebo or no intervention for chronic rhinosinusitis. The Cochrane database of systematic reviews. 2016:4:Cd011996

6. Head K, Chong LY, Hopkins C, Philpott C,
Schilder AG, Burton MJ. Short-course oral steroids as an adjunct therapy for chronic rhinosinusitis. The Cochrane database of systematic reviews. 2016;4:Cd011992.

7. Pundir V, Pundir J, Lancaster G, Baer S, Kirkland P, Cornet M, et al. Role of corticosteroids in Functional Endoscopic Sinus Surgery--a systematic review and metaanalysis. Rhinology. 2016;54(1):3-19.

8. Hopkins C, Browne JP, Slack R, Lund V Topham J, Reeves B, et al. The national comparative audit of surgery for nasal polyposis and chronic rhinosinusitis. Clinical otolaryngology: official journal of ENT-UK; official journal of Netherlands Society for Oto-Rhino-Laryngology \& Cervico-Facial Surgery. 2006;31(5):390-8

9. Hopkins $C$, Slack R, Lund V, Brown $P$ Copley L, Browne J. Long-term outcomes from the English national comparative audit of surgery for nasal polyposis and chronic rhinosinusitis. The Laryngoscope. 2009;119(12):2459-65

10. Mendelsohn D, Jeremic G, Wright ED Rotenberg BW. Revision rates after endoscopic sinus surgery: a recurrence analysis. The Annals of otology, rhinology, and laryngology. 2011;120(3):162-6.

11. van der Veen J, Seys SF, Timmermans M,
Levie P, Jorissen M, Fokkens WJ, et al. Reallife study showing uncontrolled rhinosinusitis after sinus surgery in a tertiary referral centre. Allergy. 2017;72(2):282-90.

12. Pinto Bezerra Soter $A C$, Bezerra TF, Pezato $R$, Teles Abdo TR, Pilan RM, Pinna FR, et al. Prospective open-label evaluation of longterm low-dose doxycycline for difficult-totreat chronic rhinosinusitis with nasal polyps. Rhinology. 2017;55(2):175-80.

13. Van Zele T, Gevaert P, Holtappels G, Beule A, Wormald PJ, Mayr S, et al. Oral steroids and doxycycline: two different approaches to treat nasal polyps. J Allergy Clin Immunol. 2010;125(5):1069-76 e4.

14. Bachert C, Mannent L, Naclerio RM, Mullo J, Ferguson BJ, Gevaert P, et al. Effect of Subcutaneous Dupilumab on Nasal Polyp Burden in Patients With Chronic Sinusitis and Nasal Polyposis: A Randomized Clinical Trial. Jama. 2016;315(5):469-79.

15. Schleimer RP, Schnaar RL, Bochner BS Regulation of airway inflammation by Siglec-8 and Siglec-9 sialoglycan ligand expression. Current opinion in allergy and clinical immunology. 2016;16(1):24-30.

16. Bachert C, Sousa AR, Lund VJ, Scadding GK, Gevaert P, Nasser S, et al. Reduced need for surgery in severe nasal polyposis with 
mepolizumab: randomised trial. J Allergy Clin Immunol. 2017.

17. Fokkens WJ, Lund VJ, Mullol J, Bachert C, Alobid I, Baroody F, et al. European Position Paper on Rhinosinusitis and Nasal Polyps 2012. Rhinology Supplement. 2012(23):3 p preceding table of contents, 1-298.

18. Leung RM, Dinnie K, Smith TL. When do the risks of repeated courses of corticosteroids exceed the risks of surgery? International forum of allergy \& rhinology 2014:4(11):871-6.

19. Sahlstrand-Johnson P, Hopkins C, Ohlsson B, Ahlner-Elmqvist M. The effect of endoscopic sinus surgery on quality of life and absenteeism in patients with chronic rhinosinuitis - a multi-centre study. Rhinology. 2017.

20. Hellings PW, Akdis CA, Bachert C, Bousquet J, Pugin B, Adriaensen $G$, et al. EUFOREA Rhinology Research Forum 2016: report of the brainstorming sessions on needs and priorities in rhinitis and rhinosinusitis. Rhinology. 2017, Sep 1;55(3):202-210.

21. Hellings PW, Fokkens WJ, Bachert C, Akdis CA, Bieber T, Agache I, et al. Positioning the principles of precision medicine in care pathways for allergic rhinitis and chronic rhinosinusitis - A EUFOREA-ARIA-EPOSAIRWAYS ICP statement. Allergy. 2017.

22. 22. Rudmik L, Smith TL, Schlosser RJ Hwang PH, Mace JC, Soler ZM. Productivity costs in patients with refractory chronic rhinosinusitis. The Laryngoscope. 2014;124(9):2007-12.

23. Magnan A, Bourdin A, Prazma CM, Albers FC, Price RG, Yancey SW, et al. Treatment response with mepolizumab in severe eosinophilic asthma patients with previous omalizumab treatment. Allergy. 2016;71(9):1335-44

24. Tonacci A, Billeci L, Pioggia G, Navarra M, Gangemi S. Omalizumab for the Treatment of Chronic Idiopathic Urticaria: Systematic Review of the Literature. Pharmacotherapy. 2017;37(4):464-80

25. Passalacqua G, Matucci A, Vultaggio A, Bagnasco D, Mincarini M, Maggi E, et al. The safety of monoclonal antibodies in asthma. Expert opinion on drug safety. 2016:15(8):1087-95

26. De Greve G, Hellings PW, Fokkens WJ, Pugin B, Steelant B, Seys SF. Endotype-driven treatment in chronic upper airway diseases. Clinical and translational allergy. 2017:7:22.

27. Hopkins C, Andrews P, Holy CE. Does time to endoscopic sinus surgery impact outcomes in chronic rhinosinusitis? Retrospective analysis using the UK clini- cal practice research data. Rhinology. 2015:53(1):18-24.

28. Hopkins C, Rimmer J, Lund VJ. Does time to endoscopic sinus surgery impact outcomes in Chronic Rhinosinusitis? Prospective findings from the National Comparative Audit of Surgery for Nasal Polyposis and Chronic Rhinosinusitis. Rhinology. 2015;53(1):10-7.

29. Muraro A, Fokkens WJ, Pietikainen S, Borrelli D, Agache I, Bousquet J, et al. European symposium on precision medicine in allergy and airways diseases: report of the European Union parliament symposium (October 14, 2015). Rhinology. 2015:53(4):303-7.

30. Bikhazi N, Light J, Truitt T, Schwartz M, Cutler J. Standalone balloon dilation versus sinus surgery for chronic rhinosinusitis: a prospective, multicenter, randomized, controlled trial with 1-year follow-up. American journal of rhinology \& allergy. 2014:28(4):323-9.

31. Chandra RK, Kern RC, Cutler JL, Welch KC, Russell PT. REMODEL larger cohort with long-term outcomes and meta-analysis of standalone balloon dilation studies. The Laryngoscope. 2016;126(1):44-50.

32. Brenner PS, Abadie WM, Weitzel EK, Thomas RF, McMains KC. Unexpected consequences of transnasal balloon dilation of the maxillary ostium. International forum of allergy \& rhinology. 2011;1(6):466-70.

33. Prince A, Bhattacharyya N. An Analysis of Adverse Event Reporting in Balloon Sinus Procedures. Otolaryngology--head and neck surgery : official journal of American Academy of Otolaryngology-Head and Neck Surgery. 2016;154(4):748-53.

34. Tomazic PV, Stammberger $H$, Koele W, Gerstenberger C. Ethmoid roof CSF-leak following frontal sinus balloon sinuplasty. Rhinology. 2010;48(2):247-50.

35. Forwith KD, Chandra RK, Yun PT, Miller SK, Jampel HD. ADVANCE: a multisite trial of bioabsorbable steroid-eluting sinus implants. The Laryngoscope. 2011;121(11):2473-80

36. Forwith KD, Han JK, Stolovitzky JP, Yen DM, Chandra RK, Karanfilov B, et al. RESOLVE: bioabsorbable steroid-eluting sinus implants for in-office treatment of recurrent sinonasal polyposis after sinus surgery: 6-month outcomes from a randomized, controlled, blinded study. International forum of allergy \& rhinology. 2016;6(6):57381.

37. Adriaensen G, Lim KH, Fokkens WJ. Safety and efficacy of a bioabsorbable flutica- sone propionate-eluting sinus dressing in postoperative management of endoscopic sinus surgery: a randomized clinical trial. International forum of allergy \& rhinology. 2017.

38. Shrime MG, Tabaee A, Hsu AK, Rickert S, Close LG. Synechia formation after endoscopic sinus surgery and middle turbinate medialization with and without FloSeal. American journal of rhinology. 2007;21(2):174-9.

39. Weber R, Keerl R, Huppmann A, Schick B, Draf W. [Effects of postoperative care on wound healing after endonasal paranasal sinus surgery]. Laryngo- rhino- otologie. 1996;75(4):208-14.

40. Lindemann J, Keck T, Rettinger G. Septalturbinate-suture in endonasal sinus surgery. Rhinology. 2002;40(2):92-4.

41. Hosemann W, Gode U, Langer F, Wigand ME. [Experimental studies of wound healing in the paranasal sinuses. II. Spontaneous wound healing and drug effects in a standardized wound model]. Hno. 1991;39(2):4854.

42. Beule AG, Scharf C, Biebler KE, Gopferich $A$, Steinmeier $E$, Wolf $E$, et al. Effects of topically applied dexamethasone on mucosal wound healing using a drugreleasing stent. The Laryngoscope. 2008;118(11):2073-7.

43. Khalmuratova R, Kim DW, Jeon SY. Effect of dexamethasone on wound healing of the septal mucosa in the rat. American journal of rhinology \& allergy. 2011;25(3):112-6.

44. Ramakrishnan VR, Kingdom TT. Does Image-Guided Surgery Reduce Complications? Otolaryngologic clinics of North America. 2015;48(5):851-9.

45. Tolisano AM, Justin GA, Ruhl DS, Cable BB. Rhinology and medical malpractice: An update of the medicolegal landscape of the last ten years. The Laryngoscope. 2016:126(1):14-9.

Wytske J. Fokkens, MD, PhD

Department of Otorhinolaryngology

Academic Medical Center

Amsterdam

the Netherlands

E-mail:w.j.fokkens@amc.uva.nl 